\title{
Passive acoustic monitoring as a complementary strategy to assess biodiversity in the Brazilian Amazonia
}

\author{
José Wagner Ribeiro Jr. ${ }^{1,2}$ Larissa Sayuri Moreira Sugai ${ }^{1,2}$ • \\ Marconi Campos-Cerqueira ${ }^{3}$
}

Received: 24 April 2017/Revised: 7 June 2017/Accepted: 12 June 2017/

Published online: 15 June 2017

(C) Springer Science+Business Media B.V. 2017

Environmental Impact Assessment (EIA) is a conservation instrument used to analyze and identify projects with potential environmental impacts, ultimately, providing mitigation strategies for decision-making (Ritter et al. 2017). In a timely debate on the conservation of the Amazon rainforest, Ritter et al. (2017) produced an essential discussion about EIAs, and reviewed three recent EIAs from infrastructure projects linked to current threats in the Brazilian Amazon basin. The authors highlighted shortfalls regarding biodiversity assessments in EIAs for the concession of roads, hydroelectric facilities and mining activities, and provided guidelines for three innovative and cost-effective methods to cope with highly diverse ecosystem: satellite remote sensing, species spectral signature, and DNA metabarcoding (Ritter et al. 2017). Although these methods are promising tools, we believe that practical solutions to sample and monitor biodiversity at large spatial and temporal scales should also take advantage from Passive Acoustic Monitoring (PAM), a reliable and cost-effective method that recently became widely employed to assess and monitor multiple animal taxa. Here, we advocate the use of PAM as an alternative and/or complementary tool for EIA in the Amazon basin.

Sounds produced by animals have long been used to assess biodiversity (e.g., point counts for birds, and standardized acoustic transect for amphibians). Although being an effective method to detect species, its use is mostly constrained by the availability of specialists (e.g., ornithologists) to conduct fieldwork (Sueur et al. 2012). In addition, auditory monitoring is rarely replicable over large temporal and spatial scales in tropical

Communicated by Dirk Sven Schmeller.

José Wagner Ribeiro Jr.

jwribeirojunior@gmail.com

1 Universidade Estadual Paulista (Unesp), Instituto de Biociências, Av. 24 A, 1515, Rio Claro, São Paulo 13506-900, Brazil

2 Programa de Pós Graduação em Ecologia e Biodiversidade, Universidade Estadual Paulista (Unesp), Rio Claro, Brazil

3 Department of Biology, University of Puerto Rico-Rio Piedras, San Juan, Puerto Rico 
forests. Recently, both commercial and low-cost Automated Acoustic Recorders (AAR) have become available, and their use for biodiversity assessment with PAM increased, rapidly becoming a cost-effective alternative for Rapid Biodiversity Assessment and All Taxa Biodiversity Inventory (Sueur et al. 2008; Wrege et al. 2017).

PAM offers programable settings for efficient wildlife recording in different habitat types, with an estimated battery and storage autonomy (Sueur et al. 2012). A sampling protocol of PAM composed of a network of AAR deployed to monitor different places simultaneously can be applied to standardize sampling designs and properly cover spatial and temporal scales in EIA (Sueur et al. 2012). Because microphones are sensible to different frequency ranges, recordings capture a wide variety of animal taxa (biophony), including cryptic and endangered species (Campos-Cerqueira and Aide 2016; Wrege et al. 2017). Additionally, PAM allows the recording of sounds produced by geophysical elements (geophony), as well as sounds produced by human activities (anthropophony; Sueur et al. 2014; Schmeller et al. 2017). These elements represent, together, an acoustic context that characterizes an ecosystem (soundscapes), whose changes through time and space can reveal how biodiversity responds to impacts from human activities (Sueur et al. 2014; Deichmann et al. 2017; Schmeller et al. 2017). This flexibility allows inventorying and monitoring species from a permanent database that remains accessible anytime, and does not require the presence of experts for fieldwork (Sueur et al. 2012; Campos-Cerqueira and Aide 2016). Species vocalizations can be identified and further be incorporated in acoustic scientific collections (e.g. The Macaulay Library, Fonoteca Neotropical Jacques VielliardFNJV, Automated Remote Biodiversity Monitoring Network-ARBIMON, and Fonoteca Zoológica-FonoZoo).

Another important advantage of PAM is the ability to directly assess noise pollution (Schmeller et al. 2017). Noise pollution can affect wildlife through changes in species behavior, mating, foraging, and movement patterns, of which impacts can scale up to population and community-level responses (Shannon et al. 2016). Empirical studies pointed noise from mining activities and road traffic as a significant driver of biodiversity declines (Duarte et al. 2015; Ware et al. 2015; Machado et al. 2017). All three infrastructure projects in Amazonia assessed by Ritter et al. (2017) present high levels of noise pollution, however, the potential impacts of noise on terrestrial and aquatic fauna in the Amazonia remains overlooked. The assessment and monitoring of these sources of noise and consequent biodiversity responses with the advent of PAM can improve the understanding of noise pollution on wildlife and support both the conclusions and guidelines of EIA.

While PAM can significantly improve temporal and spatial coverage of species monitoring in EIA, an operational challenge is to extract useful biological information from the massive amount of data that can be acquired (Gasc et al. 2017). In general, there is a tradeoff among time spent listening the recordings and the number of calls identified at the species level (Sueur et al. 2012). Fortunately, there are new tools to manipulate and extract information from large audio files, such as $\mathrm{R}$ packages (e.g., seewave, pumilioR and warbleR) and online tools such as the Remote Environmental Assessment Laboratory (REAL), ARBIMON, and Ecosounds (Gasc et al. 2017). Moreover, automated speciesidentification algorithms can be used to detect species in the recordings, although it usually focuses on a small set of species, since most algorithms are species-specific (CamposCerqueira and Aide 2016). On the other hand, soundscape analyses do not require specieslevel identification, once it represents an acoustic context, and can be used for example, to compare biodiversity patterns from different areas (Deichmann et al. 2017). Although soundscape analyses and automated species-specific identification have been successfully 
used to estimate animal distribution, species richness, and to assess natural and anthropogenic noise impacts on the fauna, these new approaches keep changing through continuous development and enhancement, and should therefore be used wisely (Sueur et al. 2014; Campos-Cerqueira and Aide 2016).

The development of PAM, along with the quantitative tools to process acoustic recordings and extract information of biodiversity allows us to assess and monitor entire ecosystems (Sueur et al. 2012; Schmeller et al. 2017). PAM can be a valuable tool for Environmental Impact Assessments, once its application can improve the procedures related to species inventory, detection of threatened and rare species, standardized protocols for sampling, and to detect human impacts on biodiversity (Sueur et al. 2012; Schmeller et al. 2017). PAM is a standardized, non-invasive method successfully used to assess marine, freshwater, and terrestrial systems to deal with a range of ecological and conservational questions (Sueur et al. 2014). For this reason, we recommend the use of PAM as a key strategy for biodiversity assessment, supporting the spatial and temporal scopes expected in EIA.

Acknowledgements JWRJ was supported by Grant \#2014/07113-8, São Paulo Research Foundation (FAPESP). LSMS was supported by Grant \#2015/25316-6, São Paulo Research Foundation (FAPESP). MCC was supported by Coordenação de Aperfeiçoamento de Pessoal de Nível Superior (CAPES) at Brazil (\#8933/13-8). We thank Raul Costa-Pereira for helpful comments on the manuscript.

\section{References}

Campos-Cerqueira M, Aide TM (2016) Improving distribution data of threatened species by combining acoustic monitoring and occupancy modelling. Methods Ecol Evol 7:1340-1348. doi:10.1111/2041210X.12599

Deichmann JL, Hernández-Serna A, Delgado JA, Campos-Cerqueira M, Aide TM (2017) Soundscape analysis and acoustic monitoring document impacts of natural gas exploration on biodiversity in a tropical forest. Ecol Indic 74:39-48. doi:10.1016/j.ecolind.2016.11.002

Duarte MHL, Sousa-Lima RS, Young RJ, Farina A, Vasconcelos M, Rodrigues M, Pieretti N (2015) The impact of noise from open-cast mining on Atlantic Forest biophony. Biol Conserv 191:623-663. doi:10.1016/j.biocon.2015.08.006

Gasc A, Francomano D, Dunning JB, Pijanowski BC (2017) Future directions for soundscape ecology: the importance of ornithological contributions. Auk 134:215-228. doi:10.1642/AUK-16-124.1

Machado RB, Aguiar L, Jones G (2017) Do acoustic indices reflect the characteristics of bird communities in the savannas of Central Brazil? Landsc Urban Plan 162:36-43. doi:10.1016/j.landurbplan.2017.01. 014

Ritter CD, McCrate G, Nilsson RH, Fearnside PM, Palme U, Antonelli A (2017) Environmental impact assessment in Brazilian Amazonia: challenges and prospects to assess biodiversity. Biol Conserv 206:161-168. doi:10.1016/j.biocon.2016.12.031

Schmeller DS, Böhm M, Arvanitidis C, Barber-Meyer SM, Brummitt N, Chandler M, Chatzinikolaou E, Costello MJ, Ding H, García-Moreno J, Gill M, Haase P, Jones M, Juillard R, Magnusson WE, Martin CS, McGeoch MA, Mihoub JB, Pettorelli N, Proenca V, Peng C, Regan EC, Schmiedel U, Simaika JP, Weatherdon LV, Waterman C, Xu H, Belnap J (2017) Building capacity in biodiversity monitoring at the global scale. Biodivers Conserv. doi:10.1007/s10531-017-1388-7

Shannon G, McKenna MF, Angeloni LM, Crooks KR, Fristrup KM, Brown E, Warner KA, Nelson MD, White C, Briggs J, McFarland S, Wittemyer G (2016) A synthesis of two decades of research documenting the effects of noise on wildlife. Biol Rev 91:982-1005. doi:10.1111/brv.12207

Sueur J, Pavoine S, Hamerlynck O, Duvail S (2008) Rapid acoustic survey for biodiversity appraisal. PLoS ONE 3:e4065. doi:10.1371/journal.pone.0004065

Sueur J, Gasc A, Grandcolas P, Pavoine S (2012) Global estimation of animal diversity using automatic acoustic sensors. In: Le Galliard JF, Guarini JM, Gaill F (eds) Sensors for ecology: towards integrated knowledge of ecosystems. CNRS Phonothèque, Paris, pp 99-119 
Sueur J, Farina A, Gasc A, Pieretti N, Pavoine S (2014) Acoustic indices for biodiversity assessment and landscape investigation. Acta Acust United Acust 100:772-781. doi:10.3813/AAA.918757

Ware HE, McClure CJ, Carlisle JD, Barber JR (2015) A phantom road experiment reveals traffic noise is an invisible source of habitat degradation. Proc Natl Acad Sci USA 112:12105-12109. doi:10.1073/pnas. 1504710112

Wrege PG, Rowland ED, Keen S, Shiu Y (2017) Acoustic monitoring for conservation in tropical forests: examples from forest elephants. Methods Ecol Evol. doi:10.1111/2041-210X12730 